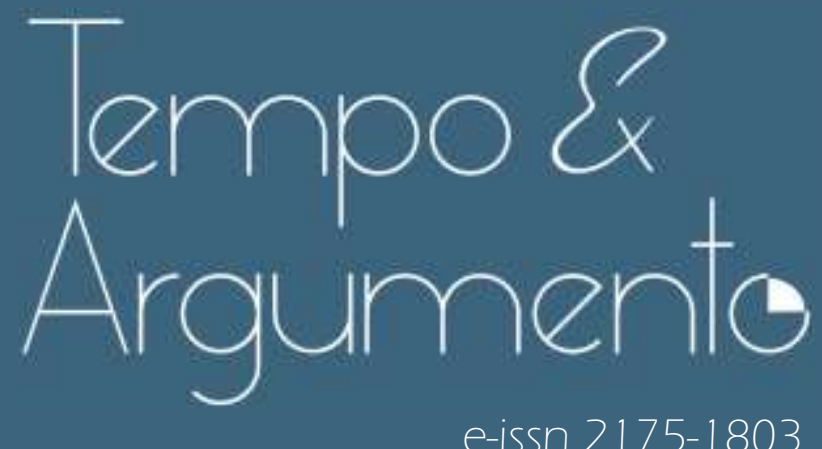

e-issn 2175-1803

\title{
Fissuras do Presentismo: Mudança Histórica nos Protestos Políticos Contemporâneos
}

- Luisa Rauter Pereira

Doutora em Ciência Política pelo Instituto de Estudos Sociais e Políticos da

Universidade do Estado do Rio de Janeiro (IESP-UERJ).

Professora do Departamento de História e do Programa de Pós-Graduação em

História da Universidade Federal de Ouro Preto (UFOP).

Mariana, MG - BRASIL

lattes.cnpq.br/8204455126116515

luisa.pereira@ufop.edu.br

D orcid.org/0000-0003-2021-0147

Para citar este artigo:

PEREIRA, Luisa Rauter. Fissuras do Presentismo: Mudança Histórica nos Protestos Políticos Contemporâneos. Tempo e Argumento, Florianópolis, v. 13, n. 34, e0301, set./dez. 2021.

do http://dx.doi.org/10.5965/2175180313342021e0301

Recebido: 03/06/2020

Aprovado: 12/06/2021 


\title{
Fissuras do Presentismo: Mudança Histórica nos Protestos Políticos Contemporâneos*
}

\begin{abstract}
Resumo
Esta década está sendo marcada por uma profunda percepção pública de mudança histórica e mesmo pelo começo de uma nova época em escala global. Este artigo argumenta que tal percepção tem raízes políticas vinculadas ao impacto dos protestos políticos como o de Junho de 2013, no Brasil, e o Occupy Wall Street nos Estados Unidos. Desse modo, analisamos o impacto de tais protestos através das narrativas e interpretações produzidas desde sua ocorrência, com foco nos livros e artigos de jornais nesses países. Pretendemos contribuir para a revisão e complexificação das principais hipóteses a respeito do tempo histórico contemporâneo vinculadas às teorias do "presenteísmo" e da "aceleração", especialmente no que diz respeito às suas conclusões a respeito da situação atual do político como âmbito de configuração da experiência coletiva do futuro. Por fim, buscamos refletir brevemente sobre as respostas possíveis do saber histórico a tais transformações.
\end{abstract}

Palavras-chave: protesto; movimentos sociais; temporalidade; presentismo; junho de 2013

\section{Cracks in Presentism: Historical Change in Contemporary Political Protest}

\begin{abstract}
This decade is being marked by a deep public perception of historical change and even as a beginning of a new epoch on a global scale. This paper argues that such a perception has political roots linked to the impact of political protests like June 2013 in Brazil and Occupy Wall Street in the Unitd States. Thus, we analyze the impact of such protests through the narratives and interpretations produced since their occurrence, focusing on books and newspaper articles in these coutries. We intend to contribute to the revision and complexification of the main hypotheses about contemporary historical time linked to the theories of "presentism" and "acceleration", especially with regard to their conclusions about the current political situation as a setting for the collective experience of the future. Finally, we seek to reflect briefly on the possible responses of historical knowledge to such transformations.
\end{abstract}

Keywords: demonstrations; social movement; temporality; presentism; june 2013.

\footnotetext{
Apoio: Fundação de Amparo à Pesquisa do Estado de Minas Gerais
} 
O sentimento de que atravessamos uma profunda mudança histórica tem se disseminado nesta década no Brasil e no mundo. Como apontou Zoltán Boldizsár Simon, a mudança climática e as descobertas tecnológicas têm contribuído para a compreensão de que vivemos hoje "mudanças sem precedentes", uma nova modalidade de mudança histórica que imagina um futuro absolutamente novo. A pandemia do coronavírus veio somar-se a essa sensação de transformação partilhada globalmente. Algumas análises recentes chegaram mesmo a vê-la como fator de crise do sistema capitalista e reinvenção do comunismo (ŽIŽEK, 2020). O campo da teoria da história tem apontado seus efeitos na experiência temporal coletiva. François Hartog, por exemplo, afirma que "enfrentamos uma crise que se tornou um fato social total" capaz de abrir "um novo tempo" que rompe o curso do tempo cronológico ordinário (HARTOG, 2021). Já Valdei Araujo e Mateus Pereira (2021) propuseram uma reflexão sobre os aspectos "atualistas" da experiência que reafirmam a confusão contemporânea entre o presente e o meramente atual.

Proponho neste artigo que uma experiência muito anterior à pandemia, a súbita ocorrência de grandes protestos de massa na abertura deste milênio no Brasil e em diversas partes do mundo, teve papel central na percepção partilhada de transposição de uma fronteira temporal. O político âmbito de representação simbólica da comunidade e de figuração dos conflitos da vida social, tem sido desde então um dos lócus da angústia partilhada em relação à profundidade e velocidade das mudanças que atravessamos como comunidade nacional e global'. Transformações na forma como as sociedades experimentam a vida

\footnotetext{
Em "Pra que serve a História em um mundo em profunda transformação", publicado no site Humanas: Pesquisadoras em Rede, em 24 de setembro de 2020, desenvolvo argumento semelhante: "além deste aspecto climático, entretanto, a compreensão disseminada de vivermos em um momento histórico gravemente específico possui também raízes de cunho imediatamente político. O mundo passa por uma onda de "desdemocratização", assinala o relatório da DeMaX (Democracy Matrix), que afere mais de 200 itens de liberdade política, igualdade e controle legal em 179 países desde 1900. O documento indica para 2019 um retrocesso nos índices democráticos de um número sem precedentes de países, havendo hoje mais "democracias deficientes" e "menos democracias funcionais". Ainda segundo o estudo, pouco mais de um quarto da população mundial vive hoje em democracias. Não se trata de algo banal. A crise nas democracias representativas e a ascensão dos neofascismos, tendo como fenômenos correlatos os negacionismos científicos e a crise geral dos parâmetros de verdade e informação públicas também constituem abalos em certa estabilidade que sustenta ainda hoje uma certa percepção de que viveríamos um fim da história ou um momento "presentista". Disponível em https://www.humanasrede.com/post/para-que-serve-ahist\%C3\%B3ria-em-um-mundo-em-profunda-transforma\%C3\%A7\%C3\%A30
} 
coletiva, agora cada vez mais em escala global, têm sido centrais nesse processo. Não trato aqui da política como uma substância da história que faz avançar as épocas do desenvolvimento histórico. Mais precisamente, pretendo analisar como a percepção de transformações fundamentalmente políticas na contemporaneidade tem conformado a compreensão coletiva mais ou menos disseminada de que estaríamos vivendo em uma "nova época histórica” ou em um "novo tempo".

Como Koselleck e Blumenberg apontaram, uma das características da modernidade, especialmente a partir da segunda metade do século XVIII, é justamente o fato de as sociedades viverem as mudanças de seu presente como "históricas", isto é, como inauguradoras de um novo tempo que rompe com o passado. A modernidade, portanto, se singulariza pela possibilidade de conferir ao tempo em si mesmo, ao "tempo puro", o qualificativo de "novo". Segundo Koselleck, as divisões em idades e períodos históricos são muito antigas e presentes em inúmeras culturas, mas costumam ser baseadas em determinantes materiais exteriores, como dinastias, reinados e Impérios. A época que se autoproclamou um "tempo novo", "completamente outro, até melhor que o anterior" (KOSELLECK, 2004) foi a única capaz de forjar uma nova historicidade que passou a perceber o passado como uma sucessão de épocas históricas diferentes em seu "nexo interno" e "espiritual", num processo que culmina na atualidade. O tempo deixou de ser visto, portanto, como uma base neutra e estável para os acontecimentos históricos, ganhando ele mesmo uma dinâmica de diferenciação qualitativa e a moderna historiografia, desse modo, pode ultrapassar a tradicional perspectiva meramente "aditiva” dos eventos pontuais, constituindo-se como um discurso universalista sobre o processo histórico de transposição epocal.

Para Blumemberg, de forma semelhante, o que singularizou a modernidade foi que esta passou a priorizar a definição dos períodos de tempo em detrimento dos pontos no tempo em sua definição de época. A palavra grega epoche significava originalmente o ponto de pausa e/ou de uma reversão no movimento de um corpo. Na filosofia cética, significava "comando" no sentido da necessária restrição ou freio ao movimento da cognição e julgamento com intuito 
de evitar o erro. Na astronomia, por sua vez, epoche significava o ponto de observação dos astros. Na historiografia moderna, o termo época passou a significar, não mais o ponto de virada, mas complexas unidades de eventos, períodos de tempo, estados de coisas e suas consequências. A modernidade, para Blumemberg, se percebeu como um tempo de ruptura com o período anterior - a Idade Media - tendendo a naturalizar a ruptura entre épocas - tidas agora como verdadeiras esfinges portadoras de um enigma próprio - como a própria dinâmica do tempo histórico em si, negligenciando o reconhecimento dos processos de continuidade e "reocupação" que também fazem parte dos processos históricos (BLUMEMBERG, 1983).

Nesse sentido, nenhuma novidade: as percepções sobre ruptura e produção de uma nova época são apenas parte da caminhada moderna. O problema é que a confirmação de minha hipótese - de que temos uma percepção ampla e partilhada de vivermos numa nova época histórica - implica, em alguma medida, a suspeita de que vivemos ainda de algum modo no tempo histórico moderno. No entanto, não têm sido raros, nas ciências humanas, diagnósticos que apontam a crise dessa forma de configuração do tempo histórico-social em direção ao "presentismo", um "regime presentista de historicidade" (HARTOG, 2003) ou um "presente amplo" (GUMBRECHT, 2014). Segundo essas interpretações, a vida contemporânea seria marcada por uma experiência de um horizonte de futuro fechado a grandes transformações e de um passado que se recusa a passar, tornando-se uma presença latente ou traumática. No campo marxista, especialmente entre autores tocados pelas reflexões da escola de Frankfurt, as análises apontam a hiperaceleração da vida e a consequente compressão do espaço tempo vivido provocados pela urgência do processo de valorização do capital, especialmente através da cultura de massa (HUYSSEN, 2000).

Um regime de urgência e instantaneidade caracteriza o capitalismo contemporâneo, marcado pela velocidade das tecnologias de comunicação, informação e consumo que minam a possibilidade de planejamento e ação política coletiva (HARVEY, 2005). Ambas as perspectivas são taxativas ao afirmar uma crise da política como capacidade de ação coletiva planejada (ROSA, 2013) 
e da adesão a amplas ideologias coletivas de transformação social. Teria havido, portanto, nas últimas décadas do século XX, uma espécie de "des-historicização" ou destemporalização" da experiência coletiva, assim como uma "despolitização" da ação humana. Analisando as manifestações de junho de 2013 no Brasil, Gumbrecht chega a afirmar peremptoriamente que, na ausência de uma visão coletiva de futuro aberto, não há ação coletiva orientada, "então não existe política." ${ }^{1}$. As massas de manifestantes unidos sem uma pauta clara evidenciariam apenas um “desejo de presença” corpórea num mundo marcado cada vez mais pelo distanciamento da virtualidade e do conhecimento. Uma questão que se impõe: numa sociedade presentista, ainda seria possível a percepção de uma ruptura de época, como acredito que estamos vivendo nesta década? Haveria hoje uma fissura na temporalidade presentista? Que tipo de ruptura temporal seria possível na sociedade atual?

Um pilar de sustentação da historicidade presentista foi a relativa estabilidade da sociedade liberal-democrática. Seguindo o argumento de Francis Fukuyama, a legitimidade dessa forma de sociedade e organização política se fortaleceu ao longo da modernidade, vencendo primeiramente a monarquia hereditária, depois o fascismo, e, mais recentemente, o comunismo. As democracias liberais, na ausência de formas alternativas de sociedade rivais, se estabeleceram como forma dominante, constituindo a "forma final de governo humano". Na célebre e contestada expressão, o autor proclama nada menos que "o fim da história". Fukuyama vai além, ao argumentar em linguagem hegeliana, que a liberal-democracia não possui as contradições internas que fazem as sociedades entrarem em crise e se transformarem. Não tendo como ser melhorada em termos de seus princípios fundamentais, apenas pode ser aperfeiçoada ou reformada. Trata-se do mais "justo regime em realidade" (FUKUYAMA, 1992, p. 338), afirma o autor².

\footnotetext{
2 Ao dar uma solução satisfatória para a eterna “luta por reconhecimento" causada pelo desejo que todo indivíduo tem de ser reconhecido como possuidor de prestígio, valor e dignidade, a liberal democracia pode, segundo Fukuyama, se consolidar de forma perene, o que não foram capazes os regimes aristocráticos anteriores e os regimes socialistas. A luta por prestígio não foi abolida na sociedade liberal, mas sim domesticada, constrangida e canalizada num sentido racional através de uma complexa série de mecanismos institucionais - o princípio da soberania popular, o estabelecimento dos direitos, o governo da lei e a separação de poderes. O desejo foi também satisfeito através da liberação do desejo aquisitivo de todos os constrangimentos na economia de mercado (FUKUYAMA, 1992).
} 
O presentismo é, portanto, também um projeto político: o avanço e consolidação da economia de mercado e o domínio mais ou menos estável do regime liberal-democrático tem como expressão ideológica o presentismo como imagem explicativa do mundo atual. O domínio da liberal-democracia e do capitalismo acarretou, de fato, se não exatamente um fim da história, a experiência coletiva de certa estabilidade política deste mundo após a Guerra Fria e a queda do muro de Berlim. As sociedades ocidentais claramente não deixaram de apresentar conflitos internos, mas não me parece descabido falar de certa estabilidade institucional e política nos últimos trinta anos em grande parte do mundo, em termos do funcionamento da liberal democracia.

No Brasil, podemos pensar que, em termos políticos, a Nova República representou uma certa estabilização. Com a promulgação da Constituição de 1988 e com as eleições democráticas livres em 1989, reorganizaram-se as instituições - a estrutura partidária, a justiça e o congresso - agora livres do julgo ditatorial. Excetuando-se a eleição de 1989 que elegeu Fernando Collor de Melo, membro de um partido pequeno e inexpressivo, e que logo sofreu um processo de impeachment, a presidência foi ocupada ao longo das décadas seguintes pelo PSDB, por oito anos, e pelo PT por quatorze anos. Os dois partidos constituíram dois polos fundamentais da social democracia brasileira: o PSDB apostando mais deliberadamente no neoliberalismo econômico e o PT representando o anseio pela justiça social. Em termos da representação parlamentar, tais partidos tiveram que lidar com um grande bloco conhecido como "centrão": representantes da burguesia nacional e da burocracia estatal, formando um misto de ex-apoiadores históricos da ditadura e de atores políticos novos e progressistas. Esse grande esquema, ao mesmo tempo em que impediu grandes transformações de distribuição de renda e propriedade, possibilitou o desenvolvimento do capitalismo brasileiro e a continuidade do projeto de desenvolvimento nacional. Impedindo rupturas violentas e transformações radicais à esquerda e à direita, mas garantindo, ao mesmo tempo, a construção de um modesto sistema público de bem-estar social, a Nova República consolidou a democracia brasileira, com transições de poder pacíficos e sem grandes abalos institucionais (NOBRE, 2013). 
Este mundo liberal-democrata marcado pela vitória do projeto capitalista sem rival dá sinais de crise hoje. E foi justamente a experiência de uma certa estabilidade política das democracias ocidentais um dos fundamentos das macrointerpretações sobre o caráter da experiência temporal contemporânea presentista. Cada vez mais nos sentimos contemporâneos de momentos históricos que se tornaram marcos epocais, definidores de novos períodos na historiografia. O passado das grandes mudanças históricas já não parece mais tão estrangeiro. No mundo, os pilares da vida política tremem. É como se o tempo histórico mesmo tivesse retomado seu movimento.

Alguns fenômenos desta década potencializaram a experiência e essa sensação de retomada da mudança histórica, em especial as grandes manifestações que de 2011 a 2013 abalaram os sistemas políticos e a vida social de diversos países. Como sabemos, o ano de 2011 iniciou uma avalanche de protestos pelo mundo: as manifestações na Praça Tahir no Egito, que se espalharam pelo mundo árabe, do Norte da África e Oriente Médio, no fenômeno que ficou conhecido como Primavera Árabe, o Occupy Wall Street nos Estados Unidos, os Indignados na Espanha, os protestos na Praça Syntagma, na Grécia e as Manifestações de 2013 no Brasil são os mais evidentes. Não é exagero dizer que muito da dinâmica do mundo atual se deve a esses eventos, considerados em seus locais de origem, pontos de virada da experiência histórica recente.

Chris Lorenz (2019) apontou que a hipótese presentista de Hartog redundou numa grande descrição de uma época: a época presentista. A categoria presentismo teria sido marcada pela ambiguidade da categoria "regime de historicidade" que, se pretende uma ferramenta teórica puramente analítica. Ao ser posta em análises históricas, acabou reproduzindo noções típicas do historicismo que quis desconstruir, isto é, descrições generalizantes de épocas históricas. Em relação especificamente ao "regime presentista", este acabou, portanto, se confundindo com a descrição de uma "época” iniciada em algum momento após a Segunda Guerra Mundial, marcada por um grande "nós” capaz de englobar todas as experiências particulares nela contidas. Nessa experiência coletiva, o passado seria experimentado de forma presentista, como memória, patrimônio e dívida em relação às experiências de sofrimento histórico de 
determinados segmentos sociais, perdendo seu caráter de alteridade, e o futuro vislumbrado como precaução e reação de curto prazo, sem a extensão dos projetos modernos. Este futuro da época presentista seria, portanto, incapaz de fazer frente à "crise temporal" que a caracteriza (HARTOG, 2016).

Da mesma forma, a concepção de um presente amplo de Hans Ulrich Gumbrecht também aponta em alguma medida para uma compreensão epocal do tempo. "Entre o inacessível futuro novo e o novo passado que já não deixamos (já não queremos deixar para trás), começamos a sentir que o presente se torna cada vez mais amplo e o ritmo do tempo se faz mais lento", nos diz o autor (GUMBRECHT, 2014). Ora, a primeira pessoa do plural evidencia uma difusa compreensão da totalidade da experiência que pode facilmente ser lida como uma unidade no tempo histórico no sentido do historicismo moderno. A imagem contida no título de um de seus livros mais populares "Nosso amplo presente", sem dúvida, enseja uma imagem totalizante do que seria uma época presentista.

Ora, por mais que as hipóteses presentistas sejam sedutoras e de fato bastante esclarecedoras de uma série de elementos das experiências históricas atuais, concordo com Chris Lorenz de que este "nós" constitui uma forma de obscurecer experiências, existências e formas de ação política diversas que igualmente caracterizam isso que chamamos de mundo atual. Assim como Zoltán Boldizsár Simon destacou, com foco na problemática do clima e da tecnologia hoje, é preciso adensar a descrição do mundo contemporâneo, incluindo fenômenos diversos não levados em conta nestas hipóteses, que igualmente têm impactado a forma como a sociedade tem enxergado seu futuro coletivo. O tempo histórico, suas fronteiras e distâncias são atos performativos de caráter ético-político e não substâncias absolutas independentes do observador (BERVENAGE, 2013). Portanto, a história é menos o que nós habitamos, somos impulsionados por, somos determinados por, do que aquilo pelo que lutamos contra, brigamos por" (BROWN, 2011, p. 55) e o tempo uma "construção política" e não mais uma experiência compartilhada (BADIOU, 2008, p. 105). Portanto, quando falamos do presente, não devemos tratá-lo como uma época histórica fechada que engloba tudo e todos, mas como um campo de disputas políticas pelo tempo. 
O presentismo, portanto, não é uma descrição neutra da realidade, mas uma ação performática de ordenamento temporal fruto, em grande medida, da estabilização de um certo projeto de mundo vencedor: o capitalismo neoliberal e a liberal democracia. Portanto, devemos sempre deixar nossas análises do contemporâneo serem permeadas pelas tensões que constituem todas as situações históricas, seus múltiplos projetos e modos de vida em disputa, a fim de que a realidade possa ser considerada, não como a implantação inequívoca de um modo de vida, mas, como sugere Jérôme Baschet, "a ação progressiva dentro de um conjunto de opções possíveis" (BASCHET, 2018, p. 12). Deste modo, a crítica teórica do presentismo passa também por uma recusa política a estarmos "presos no presente perpétuo e a atribuir ao estado de fato um caráter de inevitabilidade" (BASCHET, 2018, p. 12). Nesse esforço, prestar atenção aos movimentos populares, protestos políticos e ativismos ${ }^{3}$, à esquerda e à direita, que marcaram esta década, se torna imperativo para a teoria da história.

\footnotetext{
${ }^{3}$ Um intenso debate sobre os movimentos sociais vem ocorrendo desde a década de 1960 nas ciências sociais (ALONSO, 2009; GOHN, 1997). Diante das dificuldades que as novas dinâmicas do capitalismo impunham às teorias da revolução proletária e de novas demandas sociais que extrapolavam o tradicional conceito de classe social, desenvolveram-se novas tentativas de compreensão de uma nova dimensão da política: os novos movimentos sociais. Nos anos 1960, a partir da reflexão de Adorno (1985), as interpretações partiram primeiramente da psicanálise e da crítica da cultura e apontaram a irracionalidade das novas demandas numa sociedade massificada. Na década seguinte, a racionalidade dos agentes na "mobilização de recursos" diante dos benefícios a serem obtidos com as mobilizações se tornariam os objetos de primeiro plano. Desenvolveram-se também, explicações de cunho histórico que viram os movimentos sociais como fenômenos peculiares à estrutura dos estados nacionais modernos que teriam enfraquecido as formas locais de expressar demandas e aberto um novo campo de oportunidades para ações políticas paralelas à estrutura representativa (TILLY, 1993).

No final dos anos 1970, foram apontadas as especificidades históricas dos "novos movimentos sociais". Retornando de certa maneira às primeiras preocupações de Adorno (1985), Alain Tourraine (1978) e Jurgen Habermas (1981) argumentaram que mudanças macroestruturais na natureza do capital transformaram profundamente o caráter das lutas políticas, que passaram a se dar mais no campo cultural do que no econômico. Os movimentos sociais teriam se tornado agentes de pressão social, voltados para persuadir a sociedade civil sobre temas como democratização social, ecologia, costumes, identidades, qualidade de vida e diretos humanos. Nas últimas três décadas, as atenções têm se voltado para o estudo do "ativismo transnacional" pautado pelas comunicações em rede. Os fenômenos dos protestos em si, mais que os movimentos sociais em geral, têm sido objeto de novos estudos que investigaram seu caráter simbólico, afetivo e emocional das manifestações atuais (GOODWIN, 2000, 2001). Nestes estudos, foram focalizadas a retórica dos ativistas e suas narrativas, a construção e disseminação de histórias pelos ativistas através, especialmente da internet, tem sido, não apenas um veículo de informações, mas a condição para a emergência dos movimentos sociais atuais (POLLETTA, 2013). O surgimento de uma sociedade civil global, interconectada pela comunicação em rede em tempo real tem sido, para muitos intérpretes, uma nova forma de fazer política, diversa daquela que ocorre nos tradicionais locais de participação e interpretação (CASTELLS, 2012).
} 
Os Protestos contemporâneos e a percepção da mudança histórica: os casos do Occupy Wall Street e das Jornadas de Junho de 2013

Consolidou-se na esquerda internacional uma interpretação de que as grandes manifestações de massa e revoltas populares corridas mundialmente a partir de 2011, mais do que manifestar um desejo ou um projeto de mudança social e econômica, seriam uma espécie de recomeço ou renascimento da própria história. Para o filosofo Alain Badiou, tais movimentos populares massivos seriam respostas à generalização do capitalismo globalizado caracterizado pelo poder ilimitado das oligarquias financeiras. Diferente de muitas outras revoltas, seriam "revoltas históricas", já que sua localização é mais limitada, desenvolvendo-se em espaços ocupados que prometem uma temporalidade de longa duração. Além disso, sua composição não é uniforme e setorizada, mas representa de alguma forma a totalidade do "povo" e, mais do que uma rebelião, as revoltas apresentam demandas comuns. Para Badiou "uma era foi aberta, se não da possibilidade, então ao menos da 'possibilidade da possibilidade' de uma subsequente ruptura criadora de um desdobramento histórico imprevisto" (BADIOU, 2012, p. 28).

A vasta bibliografia a respeito das manifestações populares nesta década ${ }^{4}$ demonstra essa sensação de que se tratava de um fenômeno novo e de peso histórico. Tomando o caso do movimento Occupy Wall Street que tomou dezenas de cidades norte-americanas para protestar contra o domínio da democracia pelos interesses das corporações financeiras, muitos exemplos de um sentimento de mudança e ruptura aparecem. Para a jornalista da revista Magazine, Sara Gelder, apoiadora e participante ativa, o movimento teria fornecido uma razão para acreditar que "nós, o povo podemos tomar o encargo de nosso destino, não sendo mais "relegados à margem da história. Estamos fazendo história", afirma a ativista (GELDER, 2011). Chris Edge, também ativista, jornalista e bispo presbiteriano, declarou que o capitalismo contemporâneo está em vias de colapso, não sendo mais capaz de produzir uma sociedade e uma

\footnotetext{
${ }^{4}$ Para viabilizar o processo de pesquisa, privilegiei os livros publicados especificamente sobre os protestos entre 2013 e 2018, deixando de lado a enorme quantidade de artigos acadêmicos publicados. Evidentemente, a pesquisa nas bases de dados de artigos poderia enriquecer a análise.
} 
narrativa de vida estável e crível. Uma nova narrativa estaria sendo criada durante os protestos, expondo a injustiça e a crueldade do sistema: a "revolução começou", afirma (EDGES; SACCO, 2012). Mica White, jornalista e fundador do movimento, argumenta que "uma única vitória decisiva pode mudar o curso da história”. Novas estratégias organizativas e novas ideias, embora não sejam vitoriosas no plano prático imediato, podem "liberar a energia criativa do espírito humano", causando mudança no ritmo histórico (WHITE, 2016). De maneira menos dramática, para Todd Glitlin, ativista desde os anos 1960, professor na Universidade de Columbia e especialista em movimentos sociais, o Occupy Wall Street rompeu com a "inercia da América" causada pela mídia de massa, pelo endividamento da juventude e pela cultura do sarcasmo e indiferença política. Foi, para o autor, uma "renovação" (GITLIN, 2012).

Outros participantes chegam a falar de uma "sociedade pós-jubileu", capaz de prometer um novo futuro de justiça social e um ritmo de vida mais humano (KHATIB et al., 2012). Para Ethan Earle, Occupy foi um "fenômeno único, revigorante", uma "onda de choque cultural" que alterou o quadro para futuros movimentos progressistas no país e que será sentida por anos ou décadas (EARLE, 2012). O movimento Occupy foi visto como o momento em que um ciclo foi quebrado (em que se esperava pelo corte de vagas de trabalho, o próximo assalto à classe trabalhadora ou a próxima crise financeira). "Algo aconteceu" quando uma nova "chama ardeu", um "aroma de eletricidade" foi sentido e uma "uma chamada de clarim foi ouvida" apontam Don Hanzen, Tara Lohan e Lyn Parramore. Uma "faísca pegou fogo", reabrindo "o templo da possibilidade", continuam. Occupy Wall Street teria aberto, assim, a visão de "um novo mundo" de justiça social, assim como todos os grandes movimentos de mudança "em nossa história" - a abolição da escravidão, o sufrágio das mulheres, o movimento pelos direitos civis (HAZEN; LOHAN; PARRAMORE, 2011). Os movimentos iniciados em 2011 devem ser olhados como o primeiro estágio numa longa jornada histórica para os movimentos progressistas pelo mundo (TUFEKCI, 2017).

A sensação de profunda mudança e retomada do tempo histórico trazida pela presença física impressionante das grandes manifestações do início da presente década trouxe de volta para a reflexão política no campo da esquerda 
o tempo como "aqui e agora". Os movimentos sociais hoje são de fato muito preocupados com o problema do tempo, pois parece cada vez mais claro que "precisamos reimaginar a anti-opressão menos como uma questão de ganhar espaço e mais como uma questão de ganhar tempo" (HAIVEN; KHASNABISH, 2014). Muitas análises apontam a necessidade de se libertar da experiência e conceituação do tempo do liberalismo, que considera o passado como âmbito da ignorância, da opressão e do preconceito, e o presente abençoado e positivo por ser capaz de incluir aqueles que eram antes marginalizados e discriminados. Não basta uma celebração da diferença e dos novos direitos, sendo preciso "horizontes compartilhados", produzir solidariedade e autonomia dentro da sociedade acelerada e atomizada do capitalismo atual. É preciso "prefigurar" o político e o social que o movimento busca estabelecer, rompendo com a temporalidade dominante. É no aqui e agora, e não num futuro revolucionário, que o novo mundo será construído (GOYENS, 2017). Chis Edges e Joe Sacco, por exemplo, analisam como o movimento Occupy "capturou o espírito comunitário das tribos nativas americanas", buscando produzir no presente imediato uma sociedade horizontal, sem lideranças (EDGES; SACCO, 2013, p. 34). O movimento tentou constituir um "lar" "no ambiente inóspito de Zuccotti Park para a diversidade dinâmica da experiência humana" (WELTY; MEGHANA; MALONE, 2013). A experiência de Liberty Park foi "um potente antídoto [...] com sua comida, livros, música gratuitos, assembleias gerais, foi o exercício de política de ajuda mútua, solidariedade e cuidado. Um simples e inautorizado ato de amor" (KHATIB; KILLJOY; MCGUIRE, 2013). A presença física nas ruas e praças norte-americanas teria criado, na visão dos participantes, um mundo à parte e um outro tempo, apartado e em contradição com o espaço-tempo do capitalismo avançado em que vivemos.

Assim, ocupando as praças e ruas dos Estados Unidos e produzindo ali uma miniatura de sociedade, seria possível produzir uma quebra na dinâmica temporal. Como lembrou Judith Butler, o povo na rua reunido possui um peso existencial nas sociedades democráticas. A presença dos corpos em performance é capaz de falar por si antes de qualquer discurso. Trata-se de um "ato mágico" que irrompe na realidade e tem significado e existência em si 
mesmo para além de qualquer demanda específica. Em suas palavras, "a assembleia ja está falando antes de pronunciar qualquer palavra” (BUTLER, 2015, p. 78). A vontade popular é mostrada pelo simples fato de os corpos estarem reunidos, sendo um fenômeno em si mesmo, uma presença, de onde parte a soberania popular que nunca é inteiramente alienada ao Estado.

Essa experiência da ocupação das praças levou a uma retomada do clássico debate Kairos versus Cronos: o "tempo do agora", da ação e da revolução, contraposto ao tempo linear e cronológico do progresso. Para Jason Adams, em Occupy Time. Technoculture, Immediacy and Resistance after Occupy Wall Street, não basta que a resistência se dê no tempo do kairos revolucionário da modernidade, pois o capitalismo atual se efetua igualmente nesta temporalidade kairórica do puro agora. Partindo das reflexões de Paul Virilio e Agamben, uma vez que vivemos hoje no tempo, não mais da aceleração progressiva, mas da imediaticidade e simultaneidade é preciso desenvolver novas formas de resistência. Portanto, os movimentos políticos contemporâneos de esquerda precisam fazer uma revisão crítica sobre o que significa o potencial revolucionário do kairos. Para Adams, as grandes revoltas e manifestações contemporâneas como o Occupy representam a efetivação dessa nova estratégia, ao realizar, não mais uma revolução pontual, mas uma "ocupação do tempo", criando formas mais plásticas de resistência, como ação e pensamento que levem em conta a imediaticidade e a simultaneidade da temporalidade atual (ADAMS, 2014).

No Brasil, as Jornadas de Junho de 2013 têm aparecido em análises acadêmicas e de intervenção política de todos os matizes como um verdadeiro ponto de ruptura epocal na história nacional recente ${ }^{5}$. Se nos Estados Unidos, o impacto do Occupy Wall Street se limitou mais a trajetória das esquerdas, no Brasil, o impacto dos movimentos de massa ocorridos em centenas de cidades brasileiras tem sido apontado como capaz de transformar os destinos da nação como um todo. O entusiasmo das esquerdas nas primeiras análises que surgiram foi grande: a história havia recomeçado. A multidão estava novamente nas ruas,

\footnotetext{
5 Privilegiei nesta análise os livros publicados especificamente sobre Junho de 2013 ou que possuam ao menos um capítulo dedicado ao tema. No que se refere ao uso de jornais e revistas de grande circulação, inseri na análise apenas textos de opinião que igualmente se dediquem ao tema de maneira verticalizada, excluindo notícias e textos de informação.
} 
desestabilizando um momento histórico em que as grandes mudanças pareciam impossíveis. Para o professor, ativista e blogueiro Bruno Cava (2013), participante ativo nos protestos, as jornadas foram uma oportunidade para novamente "viver o tempo histórico" Para o autor, "se existe uma definição de momento histórico, este é um deles" (CAVA; 2013, p. 14). Para o professor da Universidade de São Paulo, Paulo Arantes, Junho de 2013 foi um momento de "ruptura", quando o país não voltaria mais a ser o mesmo (ARANTES; 2014, p. 371).

Em linha semelhante, o sociólogo Luiz Werneck Vianna relacionou Junho de 2013 a um "espírito do tempo que irrompe sem dono e sem prévia concertação" que permeou o tecido social e as instituições do Estado. O "eixo do tempo" estaria "girando em seus gonzos" a favor da democracia política, trazendo uma "mudança de época". Esta, segundo Vianna, seria fundada numa nova aproximação das pessoas comuns com a política e no rechaço público a promiscuidade entre partidos políticos, o Estado e o poder econômico. Tal mudança temporal se desenvolvera, para o autor, de forma subterrânea no processo de modernização da sociedade brasileira ao longo da redemocratização e foi sinalizada claramente nas manifestações que declararam "em alto e bom som que a sociedade não admitia ser uma base passiva para o Estado e seus governantes" (VIANNA, 2016, p. 1). A Presidente Dilma Rousseff e o Partido dos Trabalhadores não teriam sabido adequar-se a esses novos tempos, o que causara a crise que levou ao Impeachment.

Para o professor da USP, Marcos Nobre, em livro publicado naquele mesmo ano, Junho de 2013 também foi um momento de radical renovação ao encerrar o ciclo iniciado com a redemocratização brasileira após a ditadura militar e abrir a possibilidade de um novo ciclo. Para Nobre, as "Revoltas de Junho", como prefere chamar, foram o início de um novo período na democracia brasileira em que, após a consolidação do sistema democrático, as atenções se voltaram para o questionamento crítico a respeito da qualidade dessa democracia. Foi um grito de rejeição da sociedade como um todo, resguardadas suas diferenças internas, a um sistema político que não mais representava essas mesmas diferenças, o que liberou energias represadas, numa irrupção democrática. Para Nobre (2013), os efeitos históricos daquele momento serão sentidos ainda por muito tempo, 
embora as mudanças concretas futuras ainda não sejam plenamente discerníveis. Junho trouxe para o debate público, na perspectiva de Nobre, uma concepção mais alargada de democracia até então sufocada, produzindo um descompasso entre uma sociedade plural e um mundo político tendente à homogeneização conservadora. Junho abriu, assim, novamente a política para novas energias democráticas em movimento (NOBRE, 2013).

Na vertente liberal-conservadora, para além, claro, dos constantes apelos à ordem através da repressão policial, delinearam-se algumas interpretações importantes sobre 2013 como ponto de ruptura. Houve tentativas de ultrapassar o simples apelo à ordem para de fato tentar compreender o fenômeno em termos do seu significado social e político. O sociólogo e colunista político Demétrio Magnoli definiu 2013 como o maior sintoma do "fim de um ciclo" e abertura para a renovação. A "era Lula" foi, segundo o autor, marcada pela cooptação das corporações sociais (empresários e sindicatos) através de benesses do governo (crédito público e desonerações fiscais, especialmente) num contexto de crescimento do consumo interno e da renda ocasionados pelo contexto econômico internacional favorável. Junho de 2013 expressou, para o colunista, uma reação a esse estado de coisas, momento em que a sociedade foi às ruas para reafirmar sua existência, pedir para ser ouvida.

Em geral, na cobertura jornalística, da mesma forma, Junho de 2013 inaugura um novo tempo. O impacto do evento dominaria a realidade a partir de então: "13 de junho, o dia que não terminou" (FHOUTINE, 2013, p. 1), "o presente e o futuro das jornadas de junho" (COSTA, 2013, p.1), "o que restou das jornadas de Junho?” (AL HANNATI, 2013, p. 1) são exemplos de títulos de publicações que apresentam o impacto de 2013 para além da sua situação espaço-temporal de origem, portanto capaz de definir a realidade a partir de então no país. Em 2014, já se falava de um “legado” ou um "saldo” das manifestações (FELLET, 2014, p. 1). Tratava-se de evento inaugurador, capaz de seguir produzindo consequências, ao mesmo tempo, profundas e difíceis de discernir. Após a vitória da presidente Dilma Rousseff no primeiro turno das eleições presidenciais de 2014, quando se verificou notável crescimento da oposição e, portanto, um futuro político bastante nebuloso, o articulista da Revista Época Diego Escostesgui declarou "57 
milhões de votos falam: junho não acabou"16. A irresolução do evento no tempo se aprofundou nos anos seguintes com o agravamento da crise política e especialmente após o golpe parlamentar de 2016. Junho de 2013 passou a ser capaz de fornecer "lições"17, tendo, portanto, um "legado"18 e uma "herança"19. Junho aparece cada vez mais como esse interminável ano, uma força históricoexistencial poderosa, embora desordenada. Em entrevista, o geógrafo David Harvey declarou, em 2015, durante os protestos contra o governo Dilma Rousseff, que "o que aconteceu em junho de 2013 no Brasil ainda não acabou"20. Em coluna do UOL de setembro de 2015, Leandro Sakamoto, em meio ao crescimento do clima conservador nas ruas, definiu 2013 como "o ano que ainda não terminou" ${ }^{6}$.

Nos jornais?', o Occupy Wall Street foi percebido em tons menos dramáticos e grandiosos. Fundamentalmente, a esquerda, percebeu ali igualmente a irrupção de uma importante energia política, responsável por diversos frutos posteriores, mas a ideia de mudança geral de época é ausente. Embora o "fracasso" do movimento tenha sido bastante apontado, tanto pela esquerda, quanto pela direita, por ter conseguido de fato uma alteração substantiva da realidade nacional devido à sua falta de liderança e de objetivos claros e factíveis, muitos artigos salientaram como aqueles meses de protesto significaram o estopim para mudanças, que embora fossem bastante imprevisíveis, plurais e desarticuladas em seu conteúdo, eram evidentes. A professora de Yale, Bervely Gage, formulou um argumento que se tornou um lugar comum interpretativo: Occupy foi um "momento" que se transformou em um "movimento". Segundo a autora, que segue a reflexão de Zeynep Tufekci (TUFECKI, 2017), o protesto contemporâneo é visto por seus participantes não como um fim em si mesmo, ou como o evento final de uma cadeia de outros eventos, mas como um ponto inicial ou um gatilho para efeitos posteriores. Hoje

\footnotetext{
${ }^{6}$ Nesta parte, realizei uma busca simples no Google por notícias e textos da imprensa periódica cujo título contivesse as expressões "Junho de 2013", "Jornadas de Junho" ou "protestos de junho de2013" entre 2013 e 2018.

Nesta parte do artigo, apresento uma pesquisa nos campos de "opinião" e editorial dos jornais The New York Times e The Washington Post. A escolha dos dois jornais se deve, além de sua importância nacional no debate político nacional nos Estados Unidos, à sua representatividade ideológica: enquanto, o NYT representa um campo mais liberal-progressista, o The Washington Post representa o campo liberal conservador. Meu intuito foi o de obter uma visão mais ampla possível da paisagem interpretativa sobre o evento.
} 
em dia, diante da imensa capacidade de informação instantânea e mobilização nas redes sociais, e da consequente imprevisibilidade dos efeitos de um protesto, estes ganharam a conotação de um evento disparador, "um lance no meio de um emaranhado comunicativo" (GAGE, 2018, p. 1). que apenas inicia uma longa jornada de efeitos.

Assim, logo se percebeu que o movimento abriu uma "nova era de ativismo" (BLOW, 2014, p.1), pavimentando o caminho para os novos movimentos a respeito da mudança climática, contra a espionagem de cidadãos pelo governo americano, movimentos feministas e novos movimentos de rechaço ao racismo institucional, em especial à violência policial contra a população negra como o Blacks Lives Matter iniciado em 2013 e os protestos de Ferguson em 2014 (BOHLEN, 2014, p.1). O movimento teria trazido, igualmente, uma maior consciência sobre a desigualdade social (BLOW, 2013. p.1) ao cristalizar na consciência nacional o slogan "We are the 99\%", o que se verificou no maior apoio a políticos democratas-socialistas como Bernie Sanders e as eleições de Bill de Blasio e Occasio Cortez (GOLDMACHER, 2018, p. 1) De acordo com meu levantamento, a visão da direita sobre o Occupy oscilou entre a ridicularização e o silêncio. O irrealismo e a infantilidade foram salientados em artigos como o escrito por Michael Gerson no Washington Post em 2013. O ex-assessor e autor de discursos de George W. Bush, trazendo à tona a tradicional crítica conservadora às utopias e o apelo ao senso realista prático, apontou para o contágio de certos conservadores americanos pelo espírito irresponsável do Ocuppy Wall Street. E ironizou: "então a América está indo pro inferno e seremos salvos pelos métodos de Peter Pan: se você acredita, bata palmas!" (GERSON, 2013, p. 1).

De modo geral, a percepção expressa em alguns dos principais jornais norte-americanos sobre o Ocuppy Wall Street nos indica uma clara diferença em relação ao movimento no Brasil. Enquanto nos EUA, os protestos foram vistos como um marco para a reorganização das forças de esquerda, no caso brasileiro, tratou-se de um marco na trajetória de todas as forças políticas, chegando a ser percebido como um ponto de ruptura com o sistema político anterior, como um verdadeiro terremoto político capaz de alterar toda a realidade nacional. Mais do 
que um legado para os movimentos de esquerda ou de direita, 2013 foi visto como o inaugurador de uma nova época da história nacional. Nos Estados Unidos, talvez pela maior solidez do sistema político, o impacto do Occupy Wall Street não foi capaz de alterar de fato as instituições e os destinos do país, embora alguns artigos de jornal tenham algumas vezes aventado a relação entre uma maior consciência da desigualdade e a eleição de um populista ultraconservador como Donald Trump. Ao contrário de Junho de 2013, que contou com a presença de grupos e indivíduos de tendência conservadora desde os períodos iniciais, o Occupy se manteve um movimento ligado às esquerdas e, em especial, aos grupos de tendência neossocialista ou neoanarquista. Essa diferença se reflete nos termos usados para descrever o evento de Junho de 2013: abalo sísmico, terremoto, placas tectônicas, novo tempo, época, denotando sempre sua magnitude na reordenação do tempo e do espaço nacionais.

Entretanto, uma característica desse abalo sísmico temporal e dessa abertura do tempo histórico não significou uma simples retomada do tempo histórico moderno futurista. Uma análise sucinta das frases contidas nos cartazes produzidos pelos movimentos Occupy Wall Street e Junho de 2013 é reveladora neste sentido ${ }^{\text {. }}$ O próprio slogan “Occupy” possui um sentido mais geográfico que temporal e futurista: produzir presença física e bloquear o fluxo de circulação no espaço urbano. A frase "We are the 99\%", que ficou conhecida como aglutinadora de todas as reivindicações e anseios do movimento, pode ser lida como a expressão de um anseio por justiça e inclusão dentro do sistema atual. "Rebuilding grassroots democracy from below, one square at time" (OCCUPRINT PORTIFOLIO, 2012, p. 3) pode ser facilmente visto como um desejo de recriação do que já existe em termos de democracia, e não como a proposta de criação de outras possibilidades de vida. A ênfase na revolta contra altos custos dos planos de saúde e das universidades causadores do endividamento massivo dos jovens está longe de significar a proposta de uma nova sociedade.

Da mesma forma, a crítica à "ganância" das corporações financeiras em cartazes como "The love of money is the root of evil. Lets get medieval on greeds

\footnotetext{
Essa parte da pesquisa foi realizada através de busca simples no Google Imagens com as expressões Junho de 2013, Jornadas de Junho e Occupy Wall Street.
} 
ass" (OCCUPRINT PORTFOLIO, 2012, p. 5) pode ser caracterizada como uma preocupação meramente moral que não chega a propor uma mudança sistêmica no plano econômico. Muitas vezes os cartazes nos deixam a sensação de que o movimento se apaixonou por si mesmo, isto é, que tinha dificuldades de imaginar uma sociedade futura para além daquela que estava sendo vivida nas barracas da ocupação. Um cartaz específico - The Birth of Occupy Movement - apresenta a praça ocupada com seus cartazes e barracas emoldurada por dois grandes totens. Acima, um trompetista enorme parece inspirar o movimento e, abaixo, uma espécie de abre-alas com dois grandes leões protege os manifestantes.

Da mesma maneira, a frase "Save our future" denota uma perspectiva mais reativa e defensiva do que propositiva e esperançosa em relação ao futuro. 0 futuro precisa ser protegido, mais do que construído. Este cartaz é especialmente relevante. Trata-se de um desenho elaborado em que um grande urso carrega o acampamento em Zuccoty Park, protegendo-o e embalando-o. Em destaque há uma grande tenda sobre um banco de praça e um colchão. A cena retratada faz lembrar a cena final do filme Melancolia de Lars Von Trier lançado em 2011 em que as três personagens remanescentes constroem uma pequena tenda para criar uma ilusão de proteção contra o cataclisma que ocorreria em instantes com o choque de um planeta com a Terra. Essa imagem talvez possa resumir um dos sentidos de futuro do Occupy Wall Street. um futuro menos utópico, menos grandioso, menos otimista e mais cauteloso.

De forma semelhante, os cartazes que os manifestantes de Junho de 2013 no Brasil exibiram também são reveladores de uma perspectiva sobre o futuro. Assim, como no Occupy, os cartazes fizeram uso de frases de efeito, curtas e breves, muito próximas aos "memes" do Facebook e às postagens do Twitter. Mais do que explicitar reivindicações palpáveis, muitos cartazes pareciam querer produzir um efeito midiático, uma performance apropriada à lógica das redes. Como no caso norte-americano, entretanto, em Junho de 2013, a tomada das "ruas" foi um mote: "Nós somos a rede social", "Saímos do Facebook", "vem pra rua" e "Saia do Xvídeos e vem pra rua" são frases comuns presentes na produção imagética do movimento, apontando que política deveria voltar-se para o espaço público para o estar junto, para a vida coletiva, frente ao processo de virtualização 
da vida social. Assim como Occupy, o movimento brasileiro quis refundar a política. Os cartazes também evidenciaram a insatisfação generalizada com o sistema democrático. Os laços entre a comunidade e o sistema político precisavam ser refeitos. Vemos em Junho de 2013 um esforço de retomada do espaço público aqui e agora, num movimento de ocupação do espaço da política, o que acabou revelando, como sabemos, sua faceta conservadora e golpista, pedidos por ruptura institucional através do golpe militar. A retomada da política acabou dando ensejo a uma negação global da política como espaço de resolução de conflitos e construção do consenso.

Seriam os diagnósticos presentistas a respeito do político suficientes para compreender a dinâmica das manifestações políticas contemporâneas? Em certa medida sim. Por um lado, embora os analistas e participantes tenham apontado a retomada do tempo histórico e a irrupção de um novo tempo, de fato, não se delinearam claro projetos de futuro universalizantes. A retomada do tempo histórico anunciada pelos analistas e participantes de Junho de 2013 e do Occupy Wall Street não significou a retomada da temporalidade política moderna, embora a tenha anunciado em tom entusiasmado, especialmente pelas esquerdas. Por outro lado, um elemento a se destacar é justamente a emergência desses elementos da historicidade moderna em meio a uma época supostamente presentista, indicando a forte e constante atividade da disputa pelo estabelecimento de fronteiras temporais hoje. A constante negociação das fronteiras entre passado e presente abre, a todo o momento, fissuras que podem levar a crises na temporalidade dominante hoje. Logo, essa permanente politização do tempo histórico na disputa social e política atual, justamente uma das características apontadas pelas hipóteses presentistas, pode também produzir sua crise.

Mas e os elementos do tempo político constituído nas manifestações? Acredito que um ponto em comum entre os dois movimentos, Occupy e 2013, embora o caso norte-americano tenha sido mais claro neste sentido, foi a perspectiva da “ocupação". São movimentos que se dirigem, não a uma revolução capaz de romper com o antigo mundo e apresentar um novo, mas a uma ocupação do espaço-tempo, produzindo um "aqui e agora" de novas experiências 
e possibilidades. Os movimentos produziram politização intensa da realidade, desfazendo brevemente um mundo que parecia imutável, inabalável, inelutável. Como afirmou Chris Lorenz, hoje passado, presente e futuro já não são considerados como ordenados "sequenciais" e salas separadas com paredes entre elas, mas como abertas, interconectadas e espaços interativos. Uma concepção espacial do tempo parece ter substituído a ideia de tempo linear “progressivo” (LORENZ, 2014, p. 52). Parece-me que a dimensão do tempo como espaço a ocupar, de fato, foi uma tônica daqueles movimentos e sua repercussão. A concepção do legado e de sua permanência demonstra que mais do que alterar bruscamente a realidade, tais fenômenos políticos foram vistos como vetores de reflexão crítica da vida contemporânea que permanece presente no tempo-espaço, para além de sua finalização como evento cronológico.

Tais protestos e seus desdobramentos não podem ser resumidos ao que se tem chamado de "pautas identitárias", marcadas pela defesa dos direitos de grupos "específicos" da sociedade. O Occupy Wall Street, por exemplo, trouxe uma clara perspectiva universalista ao se identificar aos 99\% em oposição ao 1\% mais rico do planeta. No Brasil, as jornadas também apresentaram inicialmente tal pauta à esquerda, associada muito claramente à luta por melhores serviços públicos, mas que logo foi suplantada por outra mais conservadora identificada na luta generalista do "povo" contra as elites políticas corruptas. De toda forma, há uma dimensão claramente ampla nestes movimentos que não se opõe necessariamente à presença de pautas mais específicas, como se vê no caso norte-americano. No caso brasileiro, a marca conservadora que o movimento imprimiu acabou subsumindo pautas consideradas "de esquerda", cujos defensores inclusive se retiraram fisicamente dos protestos em dado momento.

A dimensão do passado produzida no contexto desses protestos não se resume, portanto, à luta por reparação histórica de injustiças e violências sofridas ou mera apreciação estética, como as hipóteses presentistas sugerem. No Brasil, as referências à ditadura militar e nos Estados Unidos, ao passado indígena, por exemplo, são eminentemente projetivas, isto é, são passados inspiradores da ação e não passados a serem reparados ou aos quais se deve justiça no presente. 
Da mesma forma, acredito que "precaução", “medo” e “dívida” são expressões que não esgotam a dimensão do futuro que o fenômeno engendra. Embora tais dimensões existam como vimos, por exemplo, em alguns cartazes do Occupy Wall Street, o "futuro aqui e agora", isto é, o futuro que se faz na atualidade da luta ou até mesmo, durante o próprio protesto é o que está em jogo. Tais elementos da temporalidade de fenômenos políticos centrais são em grande medida invisibilizados caso hipóteses universalizantes sejam aceitas como descrições totais do contemporâneo. Há um certo saudosismo em relação ao "futuro aberto" das filosofias da história que subjaz às descrições presentistas, do qual é necessário escapar para que a complexidade do contemporâneo se revele nas análises ligadas à teoria da História.

\section{Referências}

ADAMS, Jason. Occupy Time: technoculture, immediacy and resistance after occupy Wall Street. New York: Palgrave Macmillan, 2014.

ADORNO, Theodor; HORKHEIMER, Max. Dialética do esclarecimento: fragmentos filosóficos. Rio de Janeiro: Jorge Zahar, 1985.

AL HANATI, Yuri. O que restou das Jornadas de Junho? Gazeta do Povo, São Paulo, ano 7, n. 43, p. 3, 23 nov. 2013

ALONSO, Ângela. As teorias dos movimentos sociais: um balanço do debate. Lua Nova, São Paulo, n. 76, p. 49-86, 2009.

ARAUJO, Valdei Lopes. Para além da autoconsciência moderna: a historiografia de Hans Ulrich Gumbrecht. Varia Historia, Belo Horizonte, v. 22, n. 36, jul./dez. 2006.

ARAUJO, Valdei. O direito à história: o(a) historiador(a) como curador(a) de uma experiência histórica socialmente distribuída. In: GUIMARÃES, Géssica; BRUNO, Leonardo; PEREZ, Rodrigo. Conversas sobre o Brasil: ensaios de crítica histórica. Rio de Janeiro: Autografia, 2017. p. 191-216.

BASCHET Jérôme. Défaire la tyrannie du présent: temporalités émergentes et futurs inédits. Paris: La Découverte, 2018. 
BERVENAGE, B. História, memória e violência de estado: tempo e justiça. Rio de Janeiro: Milfontes, 2018.

BITTENCOURT, Maria Clara Aquino. As narrativas colaborativas nos protestos de 2013 no Brasil: midiatização do ativismo, espalhamento e convergência. Chasqui. Revista Latinoamericana de Comunicaciónção, Quito, n. 129, ago./nov. 2013.

BLOW, Charles M. Occupy Wall Street Legacy. New York Times, New York, ano 119, n. 7400, p. 6, 13 Sep. 2013.

BLOW, Charles M. New Age of activism. New York Times, New York, ano 120, n. 7400, p. 17, 15 jun. 2014.

BLUMEMBERG, Hans. The legitimacy of the modern age. Massachusetts: The MIT Press, 1983.

BOHLEN, Celestine. Students see new hope in Bias protests. New York Times, New York, ano 120, n. 7400, p. 14, 16 Dec. 2014.

BROWN, Wendy. Introduction: politics out of History. In: POLITICS OF HISTORY. Princeton: Princeton University Press, 2001. p. 77- 101.

BUTLER, Judith. We the people: thoughts on freedom of assembly. In: NOTES TOWARD A PERFORMATIVE THEORY OF ASSEMBLY. London: Harvard University Press, 2015. p. 59.

CASTELLS, Manuel. A sociedade em rede. São Paulo: Paz e Terra, 2005.

COSTA, Henrique. O presente e o futuro das jornadas de Junho. Carta Maior, São Paulo, ano 12, n. 36. p. 12, 11 ago. 2013

DELAHAYE, Ezra. About chronos and kairos. On Agamben's interpretation of Pauline temporality through Heidegger. International Journal of Philosophy and Theology, London, v. 77, n. 3, p. 85-101, 2016.

EARLE, Ethan. A brief history of occupy Wall Street. New York: Rosa Luxemburg Stiftung, 2012.

EDGES, Chris; SACCO, Joe. Days of destruction, days of revolt. New York: Nation books, 2012.

FELLET, Um ano depois, qual o saldo dos protestos de junho de 2013? BBC News, São Paulo, ano 29, n. 189. p. 17, 13 jun. 2014.

FHOUTINE, Marie. 13 de Junho, o dia que não terminou. Carta Capital, São Paulo, ano 15, n. 73. p. 27, 16 sep. 2013. 
FUKUYAMA, Francis. The end of history and the last man. New York: The Free Press, 1992.

GAGE, Beverly. When does a moment turn into a movement? New York Times, New York, ano 120, n. 7560, p. 21, 15 May 2018.

GELDER, Sarah Ruth. This changes everything: occupy Wall Street and the 99\% movement. New York: Entertainment Corporation Staff YES! Berrett-Koehler Publishers, Incorporated, 2011.

GERSON, Michael. Conservatism meets Occupy Wall Streets. Washington Post, Washington, ano 97, n. 3.418, p. 9, 14 Oct. 2013.

GITLIN, Todd. Occupy nation: the roots, the spirit, and the promise of occupy Wall Street. New York: Itbooks, 2012.

GOHN, Maria da Glória. Teoria dos movimentos sociais paradigmas clássicos e contemporâneos. São Paulo: Edições Loyola, 1997.

GOLDMACHER, Shane. Ocasio-Cortez Toppled a Giant. Are These N.Y. Democrats Next? New York Times, New York, ano 120, n. 7560, p. 21, 15 May 2018.

GOODWIN, Jeff; JASPER, James; POLLETTA, Francesca.(orgs.). Passionate politics: emotions and social movements. Chicago: University of Chicago Press. 2001

GOODWIN, Jeff; JASPER, James; POLLETA, Fracesca. The retourn of the repressed: the fall and rise of emotions in social movement theory.

Mobilizations, Na International Journal, New York, v. 5 n. 1, p. 65-83, 2000.

GOYENS, Tom. Radical Gothan: anarchism in NYC: from Schwab 's saloon to occupy Wall Street. Urbana: University of Illinois Press, 2017.

GUMBRECHT, Hans Ulrich. Our broad present: time and contemporary culture. New York: Columbia University Press, 2014

HABERMAS, Jürgen. New social movements. Telos, New York, n. 49, p. 111-154, 1981

HABERMAS, Jürgen. The postnational constellation: political essays. Cambridge: Polity Press, 2001.

HAIVEN, Max; KHASNABISH, Alex. The radical imagination: social movement research in the age of austerity. London: Zed Books, 2014.

HARTOG, François. A Covid e o tempo: 'Who is in the driver's seat? HHMagazine. Humanidades em Rede, Mariana, p. 12-22, 03 fev. 2021. 
HARTOG, François. Régimes d'historicité: présentisme et expériences du temps. Paris: Éditions du Seuil, 2003.

HAZEN, Don; LOHAN, Tara; PARRAMORE, Lynn. The 99\%: how the occupy Wall Street movement is changing America. San Francisco: AlterNet, 2011.

HUYSSEN, Andreas. Seduzidos pela memória: arquitetura, monumentos, mídia. Rio de Janeiro: Aeroplano, 2000. p. 8-40.

KHATIB, Kate; KILLJOY, Margaret; MCGUIRE, Mike. We are many: reflections on movement strategy: from occupation to liberation. New York: editora AK Press, 2012.

KOSELLECK, Reinhart. Neuzeit' remarks on the semantics of modern concepts of movement. In: FUTURE PAST: on the semantics of historical time. New York: Columbia University Press, 2004.

LORENZ, Blurred Lines. History, Memory and the Experience of Time. International Journal for History, Culture and Modernity, Amsterdam, v. 2, n. 1, p. 43-63, 2014.

NICOLAZZI Fernando. Muito além das virtudes epistêmicas: o historiador público em um mundo não linear. Revista Maracanan, Rio de Janeiro, n. 18, p. 18-34, jan./jun. 2018.

NOBRE, Marcos. Choque de democracia: razões da revolta. São Paulo: Editora Schwarcz, 2013.

PEREIRA, Mateus H. de Faria; ARAUJO, Valdei Lopes de V. Atualismo: pandemia e historicidades no interminável 2020. Estudos Ibero-Americanos, Porto Alegre, v. 47, n. 1, e39802, 2021. Disponível em https://doi.org/10.15448/1980864X.2021.1.39802. Acesso em: 09 mar. 2019.

POLLETTA, F. It was like a fever: storytelling in protest and politics. Chicago: Chicago University Press, 2006.

ROSA, Harmut. Social acceleration: a new theory of modernity. New York: Columbia University Press, 2013.

SOUZA, Francisco Gouvêa de; GAIO, Géssica Guimarães; NICODEMO, Thiago Lima. Uma lágrima sobre a cicatriz: O desmonte da universidade pública como desafio à reflexão histórica (\#UERJResiste). Revista Maracanan, Rio de Janeiro, n. 17, p. 71-87, jul./dez. 2017.

STOCKMAN, Farah. 'Yes, I'm Running as a Socialist.' Why Candidates Are Embracing the Label in 2018. New York Times, New York, ano 120, n. 7.560, p. 21, 20 Apr. 2018. 
TILLY, C. From mobilization to revolution. New York: Newberry Award Records, 1978.

TOLES, Tom. Occupy Wall Street Just Won. New York Times, New York, ano 119, n. 7560, p. 6, 13-15 Jul. 2015

TOURAINE, Alain. La voix et le regard. Paris: Seuil, 1978.

TUFECKI, Zeinep. Twitter and Tear Gaz: the power and fragility of network protest. New Haven: Yale University Press, 2017.

VIANNA, Luiz Werneck. O espírito do tempo e nos. O Estado de São Paulo, São Paulo, p.14-15, 1 maio 2016.

WHITE Mica. The end of the protest: a new playbook for revolution. Toronto: Penguin, 2016.

ŽIŽEK,Slavoj. Pandemia: Covid-19 e a reinvenção do comunismo. São Paulo: Boitempo Editorial, 2020.

THE OCCUPRINT PORTIFOLIO, New York, 2012.

Universidade do Estado de Santa Catarina - UDESC

Programa de Pós-Graduação em História - PPGH

Revista Tempo e Argumento Volume 13 - Número 34 - Ano 2021 tempoeargumento.faed@udesc.br 